\title{
Paradigma Holistik Kontradiksi Asas Ultimum Remedium Terhadap Asas Legalitas Dalam Penegakan Hukum Pidana Lingkungan
}

\section{Holistic Paradigm Contradiction of the Ultimate Principle of Remedium Against the Principle of Legality in Environmental Criminal Law Enforcement}

\author{
Mashuril Anwar \\ mashurilanwar97@gmail.com
}

Fakultas Hukum Universitas Lampung

Submitted: Mar 24, 2020; Reviewed: Apr 27, 2020; Accepted: Mei 18, 2020

\section{Info Artikel}

Kata Kunci: Kontradiksi; Paradigma Holistik; Ultimum Remedium.

Keywords: Contradiction; Holistic Paradigm; Ultimum Remedium.

\section{DOI:}

https://doi.org/10.25041/aelr.v1i1.2083

\begin{abstract}
Abstrak
Kemajuan wisata laut memiliki dampak positif bagi masyarakat lokal dan juga memberikan kekhawatiran pada efek negatif terhadap terumbu karang. Kerusakan terumbu karang di Indonesia saat ini mencapai 46 persen. Kerusakan mengubah terumbu karang menjadi putih dan mengancam keanekaragaman hayati dan fungsi ekosistem terumbu karang. Salah satu penyebab kerusakan adalah kandungan oksibenzon dan octinoxate pada tabir surya yang digunakan oleh para wisatawan laut. Hawaii telah menerbitkan undang-undang tentang larangan lotion tabir surya yang mengandung zat-zat ini. Tujuan dari penelitian ini adalah untuk menganalisis urgensi pelarangan tabir surya di kawasan wisata laut di Indonesia sebagai dasar penyusunan peraturan untuk melindungi ekosistem terumbu karang. Penelitian ini menggunakan pendekatan yurisdiksi normatif dan menganalisis data sekunder seperti teori hukum, peraturan perundang-undangan, dan didukung oleh beberapa penelitian tentang terumbu karang.
\end{abstract}


Hasil penelitian ini menunjukkan bahwa tabir surya mampu melindungi kulit dari paparan sinar ultraviolet yang dapat menyebabkan gangguan kesehatan akut dan kronis. Namun penggunaan oxybenzone dan octinoxate sebagai filter kimia juga berpotensi menyebabkan gangguan kesehatan. Zat-zat ini juga menyebabkan pemutihan terumbu karang bahkan pada tingkat penyelesaian terendah. Penggunaan tabir surya telah diatur di beberapa tempat di dunia. Mengacu pada teori hukum progresif, larangan menggunakan tabir surya yang mengandung oksibenzon dan octinoxate di kawasan wisata laut dianggap mendesak karena bentuk hukum yang dibuat untuk kesejahteraan manusia dan itu menjadi solusi bagi ketidakhadiran hukum mengenai perlindungan terumbu karang di Indonesia. Adaptasi hukum selektif dan bertanggung jawab yang didasarkan pada fakta dan data lingkungan hidup sesuai dengan teori hukum responsif.

Abstract
The advancement of marine tourism has a
positive impact on local communities and also
raises concerns about negative effects on coral
reefs. Damage to coral reefs in Indonesia
currently reaches 46 percent. The damage turns
coral reefs white and threatens biodiversity and
the function of coral reef ecosystems. One of the
causes of damage is the oxybenzone and
octinoxate content in sunscreens used by marine
tourists. Hawaii has issued a law banning
sunscreen lotions containing these substances.
The purpose of this study was to analyze the
urgency of banning sunscreens in marine
tourism areas in Indonesia as a basis for
drafting regulations to protect coral reef
ecosystems. This study uses a jurisdictional
normative approach and analyzes secondary
data such as legal theory, laws and regulations,
and is supported by several studies on coral
reefs. The results of this study indicate that
sunscreen can protect the skin from exposure to
ultraviolet rays which can cause acute and
chronic health problems. However, the use of
oxybenzone and octinoxate as chemical filters
also has the potential to cause health problems.


These substances also cause coral bleaching even at the lowest settlement level. The use of sunscreen is regulated in several parts of the world. Referring to the progressive legal theory, the prohibition of using sunscreens containing oxybenzone and octinoxate in marine tourism areas is considered urgent because the form of the law is made for human welfare and it is a solution to the absence of laws regarding the protection of coral reefs in Indonesia. Adapt selective and responsible law based on facts and environmental data in accordance with responsive legal theory.

\section{A. Pendahuluan}

Asas hukum merupakan prinsip dasar hukum yang abstrak sekaligus melatar belakangi peraturan konkret dan pelaksanaan hukum. ${ }^{1}$ Dalam hukum dikenal beberapa asas diantaranya asas ultimum remedium yang berarti bahwa pidana merupakan sarana terakhir, dan asas legalitas yang bermakna bahwa tidak ada suatu perbuatan dapat dipidana jika tidak ada aturannya. Dewasa ini terdapat banyak ragam tindak pidana diantaranya di bidang lingkungan hidup. ${ }^{2}$ Sebagaimana amanat UUD 1945 bahwa lingkungan yang baik dan sehat adalah hak asasi dan hak konstitusional warga negara. Oleh karenanya lingkungan hidup harus dilindungi dan dikelola dengan baik. Hukum pidana menjadi salah satu instrumen penegakan hukum lingkungan selain penegakan hukum administrasi dan perdata. Penegakan hukum pidana di bidang lingkungan hidup diatur dalam Pasal 100 ayat (2) Undang-Undang Nomor 32 Tahun 2009 tentang Perlindungan dan Pengelolaan Lingkungan Hidup. Pada intinya Pasal 100 ayat (2) memuat ketentuan bahwa sanksi pidana hanya dapat dijatuhkan apabila sanksi administratif tidak dipatuhi dan pengulangan tindak pidana. Kemudian dalam penjelasan umum angka 6 Undang-Undang Nomor 32 Tahun 2009 tentang Perlindungan dan Pengelolaan Lingkungan Hidup, menentukan bahwa penegakan hukum pidana lingkungan memperhatikan asas ultimum remedium ${ }^{3}$ yang artinya penegakan hukum pidana adalah upaya terakhir apabila penegakan hukum administrasi tidak berhasil.

Penerapan asas ultimum remedium dalam Pasal 100 ayat (2) yang dikuatkan oleh penjelasan umum angka 6 Undang-Undang Nomor 32 Tahun 2009 tentang Perlindungan dan Pengelolaan Lingkungan Hidup, bertolak belakang dengan asas legalitas yang tertuang dalam KUHP. Menurut asas legalitas, suatu perbuatan yang telah diatur sebagai tindak pidana maka dapat dipidana. Pasal 100 ayat (1) secara tegas telah menentukan sanksi pidana bagi pelaku pengerusakan lingkungan yakni pidana penjara paling lama tiga tahun dan denda paling

\footnotetext{
${ }^{1}$ Radita Ajie, "Batasan Pilihan Kebijakan Pembentuk Undang-Undang (Open Legal Policy) Dalam Pembentukan Peraturan Perundang-Undangan Berdasarkan Tafsir Putusan Mahkamah Konstitusi,” Jurnal Legislasi Indonesia (Indonesian Journal of Legislation) 13, no. 2 (2016): 111-20.

${ }^{2}$ Ridwan Rangkuti, "Pertanggungjawaban Korporasi Terhadap Tindak Pidana Lingkungan Hidup Menurut Undang- Undang Nomor 23 Tahun 1997," JUSTITIA: Jurnal Ilmu Hukum Dan Humaniora 1, no. 1 (2018): 253, https://doi.org/10.31604/justitia.v1i1.253-270.

${ }^{3}$ Lidya Suryani Widayati, "Ultimum Remedium Dalam Bidang Lingkungan Hidup," JURNAL HUKUM IUS QUIA IUSTUM 22, no. 1 (2015): 1-24, https://doi.org/10.20885/iustum.vol22.iss1.art1.
} 
banyak tiga milyar rupiah. Artinya, perbuatan yang dimaksud dalam Pasal 100 ayat (1) Undang-Undang Nomor 32 Tahun 2009 tentang Perlindungan dan Pengelolaan Lingkungan Hidup dapat dipidana. Namun, dengan adanya asas ultimum remedium yang tersirat dalam Pasal 100 ayat (2), terhadap pelaku pengrusakan lingkungan tidak dapat langsung dijatuhi pidana melainkan melalui sanksi administratif terlebih dahulu. ${ }^{4}$ Sanksi administratif sangat efektif diterapkan jika benar-benar dilaksanakan, namun apabila tidak dilaksanakan akan terjadi pengulangan perbuatan yang akan semakin merusak lingkungan. Mengingat ketentuan pidana terhadap pelaku pengrusakan lingkungan telah diatur dalam Undang-Undang Nomor 32 Tahun 2009 tentang Perlindungan dan Pengelolaan Lingkungan Hidup, oleh karena itu berdasarkan asas legalitas pelaku pengrusakan lingkungan disamping dijatuhi sanksi administratif juga dijatuhi pula sanksi pidana. ${ }^{5}$ Hal ini dimaksudkan agar memacu pelaku untuk melaksanakan sanksi administratif dan tidak mengulangi perbuatannya. Selain itu, hukum pidana dan hukum administrasi merupakan dua ranah hukum yang berbeda, penjatuhan sanksi administrasi tidak menggugurkan sanksi pidana. ${ }^{6}$

Ketentuan asas ultimum remedium dalam Pasal 100 ayat (2) dan penjelasan angka 6 Undang-Undang Nomor 32 Tahun 2009 tentang Perlindungan dan Pengelolaan Lingkungan Hidup juga tidak selaras dengan prinsip paradigma baru dalam penegakan hukum lingkungan yakni paradigma holistik. ${ }^{7}$ Penegakan hukum lingkungan dalam paradigma holisitk menghendaki penggunaan semua sarana hukum baik administrasi, perdata, dan pidana secara bersamaan. Sedangkan ketentuan Pasal 100 ayat (2) yang dikuatkan dengan penjelasan angka 6 Undang-Undang Nomor 32 Tahun 2009 tentang Perlindungan dan Pengelolaan Lingkungan Hidup mengedepankan asas ultimum remedium dengan membatasi penerapan sanksi pidana. Pasal 100 ayat (2) menghendaki penggunaan sanksi pidana diterapkan ketika sarana hukum adminsitrasi tidak dipatuhi.

Berdasarkan uraian diatas, permasalahan dalam kajian ini mengenai bagaimana kontradiksi asas ultimum remedium dengan asas legalitas dalam penegakan hukum lingkungan? dan bagaimana kontradiksi asas ultimum remedium dengan paradigma holistik dalam penegakan hukum lingkungan? Metode yang digunakan dalam kajian hukum ini yakni yuridis kualitatif, yaitu dengan meneliti bahan hukum sekunder. Pendekatan yang digunakan yakni pendekatan perundang-undangan, kemudian data dianalisis dengan metode kualitatif.

\section{B. Pembahasan}

\section{Kontradiksi Asas Ultimum Remedium Terhadap Asas Legalitas Dalam Penegakan Hukum Lingkungan}

Penegakan hukum lingkungan meliputi beberapa bidang hukum seperti hukum administrasi, hukum perdata serta hukum pidana. Penegakan hukum lingkungan mengedepankan asas ultimum remedium, dengan kata lain hukum pidana merupakan sarana terakhir dan mengutamakan sarana hukum administrasi. Hukum pidana akan diterapkan

\footnotetext{
${ }^{4}$ Grahat Nagara, "Perkembangan Sanksi Administratif Dalam Penguatan Perlindungan Lingkungan Terkait Eksploitasi Sumber Daya Alam (Studi Kasus: Sektor Perkebunan, Pertambangan, Dan Kehutanan)," Jurnal Hukum Lingkungan Indonesia 3, no. 2 (2017): 19, https://doi.org/10.38011/jhli.v3i2.41.

${ }^{5}$ Nina Herlina, "Permasalahan Lingkungan Hidup Dan Penegakan Hukum Lingkungan Di Indonesia," Jurnal Ilmiah Galuh Justisi 3, no. 2 (2017): 162, https://doi.org/10.25157/jigj.v3i2.93.

${ }^{6}$ Ni Luh Putu Miarmi, "Konsep Perijinan Berwawasan Lingkungan Dalam Mewujudkan Pembangunan Berkelanjutan," Jurnal Magister Hukum Udayana (Udayana Master Law Journal) 3, no. 1 (March 27, 2014), https://doi.org/10.24843/JMHU.2014.v03.i01.p08.

7 Sigit Sapto Nugroho, "Pengelolaan Limbah Bahan Berbahaya Dan Beracun Perspektif Undang Undang Nomor 32 Tahun 2009 Tentang Perlindungan Dan Pengelolaan Lingkungan Hidup,” Sosial 14, no. 2 (2013): 60-70.
} 
ketika sarana hukum administrasi ${ }^{8}$ tidak dipatuhi atau tidak mampu menyelesaikan permasalahan lingkungan. Asas ultimum remedium diatur dalam penjelasan Pasal 6 UndangUndang Nomor 32 Tahun 2009 tentang Perlindungan dan Pengelolaan Lingkungan Hidup. Penjelasan Pasal 6 undang-undang A Quo menyatakan penegakan hukum pidana lingkungan harus memperhatikan asas ultimum remedium setelah penegakan hukum administrasi tidak berhasil. Asas ultimum remedium hanya diterapkan bagi tindak pidana formil tertentu yaitu pelanggaran baku mutu air, limbah, emisi dan gangguan. ${ }^{9}$ Penerapan asas ultimum remedium dalam penegakan hukum pidana lingkungan bertentangan dengan salah satu asas fundamental dalam hukum pidana yakni asas legalitas. ${ }^{10}$ Makna asas legalitas dimuat dalam Pasal 1 ayat (1) KUHP, yang pada intinya menyatakan bahwa suatu perbuatan dapat dipidana apabila ada ketentuan pidana yang mengaturnya. Para ahli hukum pidana menyepakati tiga makna asas legalitas yaitu: ${ }^{11}$

1) Tidak ada perbuatan yang diancam pidana apabila belum dinyatakan lebih dulu dalam aturan Undang-Undang;

2) Analogi tidak boleh digunakan dalam menentukan tindak pidana;

3) Aturan pidana tidak berlaku surut.

Menurut Von Feurbach, ada tiga makna asas legalitas yaitu: ${ }^{12}$

a. Pengenaan pidana didasarkan pada Undang-Undang;

b. Pengenaan pidana mungkin apabila perbuatan yang dilakukan diancam sanksi pidana;

c. Perbuatan yang diancam pidana tersebut mempunyai akibat hukum.

Berdasar pada asas legalitas, ketika terdapat peraturan perundang-undangan yang mengatur suatu perbuatan merupakan tindak pidana, maka pelaku dapat dipidana. Demikian yang diatur dalam Pasal 100 Undang-Undang Nomor 32 Tahun 2009 tentang Perlindungan dan Pengelolaan Lingkungan Hidup, yaitu:

1) Setiap pelanggar baku mutu air limbah, baku mutu emisi, atau baku mutu gangguan dipidana dengan pidana penjara maksimal 3 tahun dan denda maksimal 3 milyar rupiah;

2) Tindak pidana yang dimaksud ayat (1) hanya dapat dikenakan apabila sanksi administratif tidak dipatuhi atau pengulangan pelanggaran.

Kemudian Pasal 97 menyatakan bahwa tindak pidana dalam Undang-Undang Nomor 32 Tahun 2009 tentang Perlindungan dan Pengelolaan Lingkungan Hidup adalah kejahatan. Dengan demikian, kata "pelanggaran" dalam Pasal 100 ayat (2) merupakan suatu kekeliruan. Selain itu, Pasal 100 ayat (1) telah menegaskan sanksi pidana bagi pelanggar Pasal 100 ayat (1) tersebut. Namun ketentuan Pasal 100 ayat (2) yang dikuatkan oleh penjelasan angka 6 Undang-Undang Nomor 32 Tahun 2009, membatasi penerapan pidana yang ditentukan dalam Pasal 100 ayat (1) hanya apabila hukum administrasi tidak dipatuhi. Berdasarkan asas legalitas, ketika ada pelanggaran terhadap Pasal 100 ayat (1) maka seketika itu pula pidana diberlakukan. Mengingat hukum pidana dan hukum administrasi merupakan dua bidang

\footnotetext{
${ }^{8}$ Suwari Akhmaddhian, "Penegakan Hukum Lingkungan Dan Pengaruhnya Terhadap Pertumbuhan Ekonomi Di Indonesia (Studi Kebakaran Hutan Tahun 2015)," UNIFIKASI: Jurnal Ilmu Hukum 3, no. 1 (2016): 1-35, https://doi.org/10.25134/unifikasi.v3i1.404.

${ }^{9}$ Imam Budi Santoso and Taun Taun, "Penerapan Asas Ultimum Remedium Dalam Penegakan Hukum Pidana Lingkungan Hidup,” University Of Bengkulu Law Journal 3, no. 1 (2018): 15-22, https://doi.org/10.33369/ubelaj.3.1.15-22.

10 Suwardi Sagama, "Analisis Konsep Keadilan, Kepastian Hukum Dan Kemanfaatan Dalam Pengelolaan Lingkungan," MAZAHIB 15, no. 1 (2016): 20-41, https://doi.org/10.21093/mj.v15i1.590.

11 DeniSB Yuherawan, "Kritik Ideologis Terhadap Dasar Kefilsafatan Asas Legalitas Dalam Hukum Pidana," Jurnal Dinamika Hukum 12, no. 2 (May 15, 2012): 221-35, https://doi.org/10.20884/1.jdh.2012.12.2.32.

12 Jur Andi Hamzah, Hukum Pidana, Jakarta: PT. Softmedia, (2015), hlm. 49.
} 
hukum yang terpisah, pengenaan sanksi administrasi tidak menggurkan sanksi pidana, ${ }^{13}$ dengan kata lain ketentuan Pasal 100 ayat (2) tidak diperlukan. Dengan demikian ketika asas legalitas melekat pada Pasal 100 ayat (1), maka terhadap perbuatan yang melanggar baku mutu limbah, air, atau emisi langsung dikenakan sanksi pidana penjara maksimal tiga tahun dan denda maksimal tiga milyar. Sehingga asas ultimum remedium yang melekat pada Pasal 100 ayat (2) sangat bertentangan dengan asas legalitas.

Ketentuan Pasal 100 ayat (2) yang menjadikan pidana sebagai upaya terakhir tidak berdasarkan pada alasan penghapus pidana dalam KUHP. KUHP mengatur alasan penghapus pidana dalam Pasal 44 mengenai keadaan pribadi yang tidak dapat dimintai pertanggungjawaban, Pasal 48 mengenai daya paksa, Pasal 49 ayat mengenai pembelaan terpaksa, Pasal 50 mengenai melaksanakan peraturan, dan Pasal 51 mengenai perintah jabatan. Apabila dikaitkan dengan asas ultimum remedium yang diatur dalam Pasal 100 ayat (2) kemudian dikuatkan oleh penjelasan angka 6 Undang-Undang Nomor 32 Tahun 2009 tentang Perlindungan dan Pengelolaan Lingkungan Hidup, ketentuan tersebut tidak sesuai dengan alasan pengahapus pidana dalam KUHP. Oleh karena itu, ketika sanksi administrasi dijatuhkan kepada pelaku yang melanggar baku mutu limbah, air, dan emisi, tidak serta merta menghilangkan pertanggungjawaban pidananya. Begitupun sebaliknya, ketika seseorang dijatuhi sanksi pidana, tidak serta merta lepas dari sanksi administrasi mengingat hukum pidana dan hukum administrasi dua ranah hukum yang berbeda.

\section{Kontradiksi Asas Ultimum Remedium Dengan Paradigma Holistik Dalam Penegakan Hukum Lingkungan}

Paradigma holistik merupakan paradigma baru dalam penegakan hukum lingkungan yang mengutamakan nilai keadilan ketimbang ketentuan prosedural. Penegakan hukum lingkungan dengan menggunakan paradigma holistik mampu mengakomodir aspirasi dan kebutuhan masyarakat dengan memperhatikan realita yang ada dalam masyarakat. ${ }^{14}$ Penegakan hukum lingkungan dengan menggunakan paradigma holistik didasarkan pada tiga prinsip, yaitu: ${ }^{15}$

1) Menggunakan sarana hukum administrasi, hukum perdata, dan hukum pidana secara komprehensif;

2) Mengesampingkan pendekatan politik, ekonomi dan yuridis dengan mengedepankan pendekatan ekosistem;

3) Menegakkan nilai kebenaran dan nilai keadilan.

Apabila dikaitkan dengan ketentuan penerapan asas ultimum remedium dalam Pasal 100 ayat (2) yang dikuatkan oleh penjelasan umum angka 6 Undang-Undang Nomor 32 Tahun 2009 tentang Perlindungan dan Pengelolaan Lingkungan Hidup selain bertolak belakang dengan asas legalitas, ketentuan tersebut juga tidak sejalan dengan penegakan hukum lingkungan dalam paradigma holistik. Menurut pandangan holistik sanksi administrasi, perdata, dan pidana dapat diterapkan secara bersamaan, dengan kata lain ketiga jalur hukum tersebut bukan alternatif. ${ }^{16}$ Namun dengan adanya asas ultimum remedium yang tersirat dalam Pasal 100 ayat (2), dan dikuatkan dengan penjelasan umum angka 6, terhadap pelaku yang melanggar ketentuan Pasal 100 ayat (1) tidak dapat langsung dijatuhi pidana melainkan

\footnotetext{
${ }^{13}$ Marcella Lawang, "Penegakan Hukum Terhadap Pencemaran Dan Perusakan Lingkungan Objek Wisata Berdasarkan Undang-Undang Nomor 10 Tahun 2009,” LEX CRIMEN 4, no. 7 (2015): 58-66.

${ }^{14}$ Arief Budiono and Wafda Vivid Izziyana, "Ilmu Hukum Sebagai Keilmuan Perspektif Paradigma Holistik," Jurnal Hukum Novelty 9, no. 1 (2018): 89-99, https://doi.org/10.26555/novelty.v9i1.a6916.

15 Muhammad Akib, "Model Kebijakan Hukum Desentralisasi Pengelolaan Lingkungan Hidup Berbasis Pendekatan Ekosistem," FIAT JUSTISIA:Jurnal Ilmu Hukum 5, no. 2 (2014): 161-66, https://doi.org/10.25041/fiatjustisia.v5no2.58.

${ }^{16}$ So Woong Kim, "Kebijakan Hukum Pidana Dalam Upaya Penegakan Hukum Lingkungan Hidup," Dinamika Hukum 2, no. 4 (2010): 415-27.
} 
melalui sanksi administratif terlebih dahulu. Ketentuan tersebut tentu bertolak belakangan dengan prinsip paradigma holistik yang menghendaki penerapan ketiga jalur hukum (administrasi, perdata dan pidana) secara bersamaan.

Penerapan asas ultimum remedium dalam penegakan hukum pidana lingkungan menimbulkan banyak penanfsiran dan membatasi ruang gerak penegak hukum untuk memberikan efek jera terhadap pelanggar baku mutu air limbah, emisi dan gangguan. ${ }^{17}$ Karena yang diutamakan ialah sanksi administratif, kemungkinan bertambah rusaknya lingkungan semakin besar. Penerapan sanksi administratif baik untuk pemulihan lingkungan yang rusak sepanjang dipatuhi oleh pelaku, namun apabila tidak dipatuhi akan memperparah kerusakan lingkungan. Apabila sanksi pidana dijadikan sebagai upaya terakhir menimbulkan ketidakpastian hukum terhadap pelanggar Pasal 100 ayat (1). Selain itu, apabila penerapan sanksi pidana hanya dapat dilakukan ketika sanksi administrasi tidak dipatuhi, tentu akan membutuhkan waktu lama lagi untuk melihat apakah sanksi administrasidilaksanakan atau tidak. Ketentuan Pasal 100 ayat (2) yang menjadikan pidana sebagai alternatif tidak berdasarkan pada paradigma holistik dan alasan penghapus pidana dalam KUHP. Oleh karenanya, ketika sanksi administrasi dijatuhkan kepada pelaku yang melanggar baku mutu limbah, air dan emisi, tidak serta merta menghilangkan pertanggungjawaban pidananya. Begitupun sebaliknya, ketika seseorang dijatuhi sanksi pidana, tidak serta merta lepas dari sanksi administrasi mengingat hukum pidana dan hukum administrasi dua ranah hukum yang berbeda.

Penegakan hukum lingkungan yang didasarkan pada paradigma holistik memerlukan sinergi bersama para penegak hukum agar penegakan hukum lingkungan dapat dilakukan secara utuh. Sejauh ini, ketentuan dalam Undang-Undang Nomor 32 Tahun 2009 tentang Perlindungan dan Pengelolaan Lingkungan Hidup masih syarat akan kepentingan penguasa semata dan belum menitikberatkan pada pencapaian nilai keadilan dalam masyarakat. Ketentuan dalam Undang-Undang Nomor 32 Tahun 2009 tentang Perlindungan dan Pengelolaan Lingkungan Hidup khususnya Pasal 100 ayat (2) dan penjelasan angka 6, cenderung menguntungkan pelaku pengrusakan lingkungan. Dengan membatasi penerapan hukum pidana, maka pengrusakan lingkungan akan semakin merajalela. Penerapan hukum administrasi berguna bagi pemulihan lingkungan, namun tidak menjamin memberikan efek jera terhadapi pelaku. ${ }^{18}$ Oleh karena itu demi keberlanjutan ekologi, penegakan hukum lingkungan harus selaras dengan paradigma holistik, yakni menggunakan semua sarana hukum, baik administrasi, perdata dan pidana secara bersamaan.

\section{Penutup}

Berdasarkan pembahasan diatas diperoleh kesimpulan jika penerapan asas ultimum remedium dalam penegakan hukum lingkungan membatasi penerapan sanksi pidana. Penerapan sanksi pidana dilakukan ketika sanksi adminitrasi tidak dipatuhi, sehingga bertentangan dengan asas legalitas. Selanjutnya paradigma holistik menghendaki penggunaan sarana hukum administrasi, perdata, dan pidana secara bersamaan dalam penegakan hukum lingkungan. Dengan adanya ketentuan pengedepanan asas ultimum remedium dalam Pasal 100 ayat (2) yang dikuatkan dengan penjelasan angka 6 UUPPLH, maka sanksi perdata dan sanksi pidana menjadi alternatif. Penulis menyarankan beberapa hal sebagai berikut:

a. Badan eksekutif dan legislatif perlu kembali duduk bersama untuk mengharmonisasikan ketentuan dalam Undang-Undang Nomor Nomor 32 Tahun 2009 tentang Perlindungan

\footnotetext{
${ }^{17}$ Edy Lisdiyono and . Rumbadi, "Penerapan Asas Premium Remedium Dalam Perkara Pencemaran Lingkungan Hidup Akibat Limbah B3," Bina Hukum Lingkungan 3, no. 1 (2018): 1-12, https://doi.org/10.24970/jbhl.v3n1.1.

18 Rivaldo Valini, “Analisis Eksistensi Closed Circuit Television (CCTV) Pada Pembuktian Perkara Tindak Pidana Umum," Cepalo 1, no. 1 (2019): 11-20, https://doi.org/10.25041/cepalo.v1no1.1751.
} 
dan Pengelolaan Lingkungan Hidup dengan asas hukum. Hal ini penting untuk dilakukan agar penegakan hukum lingkungan memberikan keadilan dan kepastian hukum.

b. Dalam penegakan hukum lingkungan perlu dikedepankan paradigma holistik guna keberlanjutan ekologi.

\section{Daftar Pustaka}

A. Buku

Ali, Ahmad. 2007. Menguak Teori Hukum Legal Theory dan Teori Peradilan Judicial Prudance. Makasar: Kencana.

Andi Hamzah, Jur. 2015. Hukum Pidana. Jakarta: PT. Softmedia.

B. Jurnal

Akhmaddhian, Suwari. "Penegakan Hukum Lingkungan Dan Pengaruhnya Terhadap Pertumbuhan Ekonomi Di Indonesia (Studi Kebakaran Hutan Tahun 2015)." UNIFIKASI: Jurnal Ilmu Hukum 3, no. 1, 2016: 1-35. https://doi.org/10.25134/unifikasi.v3i1.404.

Akib, Muhammad. "Model Kebijakan Hukum Desentralisasi Pengelolaan Lingkungan Hidup Berbasis Pendekatan Ekosistem." FIAT JUSTISIA:Jurnal Ilmu Hukum 5, no. 2, 2014: 16166. https://doi.org/10.25041/fiatjustisia.v5no2.58.

Budiono, Arief, and Wafda Vivid Izziyana. "Ilmu Hukum Sebagai Keilmuan Perspektif Paradigma Holistik." Jurnal Hukum Novelty 9, no. 1, 2018: 89-99. https://doi.org/10.26555/novelty.v9i1.a6916.

Herlina, Nina. "Permasalahan Lingkungan Hidup Dan Penegakan Hukum Lingkungan Di Indonesia." Jurnal Ilmiah Galuh Justisi 3, no. 2, 2017: 162. https://doi.org/10.25157/jigj.v3i2.93.

Kim, So Woong. "Kebijakan Hukum Pidana Dalam Upaya Penegakan Hukum Lingkungan Hidup." Dinamika Hukum 2, no. 4, 2010: 415-27.

Lawang, Marcella. "Penegakan Hukum Terhadap Pencemaran Dan Perusakan Lingkungan Objek Wisata Berdasarkan Undang-Undang Nomor 10 Tahun 2009.” LEX CRIMEN 4, no. 7, 2015: $58-66$.

Lisdiyono, Edy, and . Rumbadi. "Penerapan Asas Premium Remedium Dalam Perkara Pencemaran Lingkungan Hidup Akibat Limbah B3.” Bina Hukum Lingkungan 3, no. 1, 2018: 1-12. https://doi.org/10.24970/jbhl.v3n1.1.

Miarmi, Ni Luh Putu. "Konsep Perijinan Berwawasan Lingkungan Dalam Mewujudkan Pembangunan Berkelanjutan." Jurnal Magister Hukum Udayana (Udayana Master Law Journal) 3, no. 1, March 27, 2014. https://doi.org/10.24843/JMHU.2014.v03.i01.p08.

Nagara, Grahat. "Perkembangan Sanksi Administratif Dalam Penguatan Perlindungan Lingkungan Terkait Eksploitasi Sumber Daya Alam (Studi Kasus: Sektor Perkebunan, Pertambangan, Dan Kehutanan).” Jurnal Hukum Lingkungan Indonesia 3, no. 2, 2017: 19. https://doi.org/10.38011/jhli.v3i2.41.

Nugroho, Sigit Sapto. "Pengelolaan Limbah Bahan Berbahaya Dan Beracun Perspektif Undang Undang Nomor 32 Tahun 2009 Tentang Perlindungan Dan Pengelolaan Lingkungan Hidup." Sosial 14, no. 2, 2013: 60-70.

Radita Ajie. "Batasan Pilihan Kebijakan Pembentuk Undang-Undang (Open Legal Policy) Dalam Pembentukan Peraturan Perundang-Undangan Berdasarkan Tafsir Putusan Mahkamah Konstitusi." Jurnal Legislasi Indonesia (Indonesian Journal of Legislation) 13, no. 2, 2016: 111-20.

Rangkuti, Ridwan. "Pertanggungjawaban Korporasi Terhadap Tindak Pidana Lingkungan Hidup Menurut Undang- Undang Nomor 23 Tahun 1997." JUSTITIA : Jurnal Ilmu Hukum Dan Humaniora 1, no. 1, 2018: 253. https://doi.org/10.31604/justitia.v1i1.253-270. 
Sagama, Suwardi. "Analisis Konsep Keadilan, Kepastian Hukum Dan Kemanfaatan Dalam Pengelolaan Lingkungan." MAZAHIB 15, no. 1, 2016: 20-41. https://doi.org/10.21093/mj.v15i1.590.

Santoso, Imam Budi, and Taun Taun. "Penerapan Asas Ultimum Remedium Dalam Penegakan Hukum Pidana Lingkungan Hidup." University Of Bengkulu Law Journal 3, no. 1, 2018: 1522. https://doi.org/10.33369/ubelaj.3.1.15-22.

Valini, Rivaldo. "Analisis Eksistensi Closed Circuit Television (CCTV) Pada Pembuktian Perkara Tindak Pidana Umum." Cepalo 1, no. 1, 2019: 11-20. https://doi.org/10.25041/cepalo.v1no1.1751.

Widayati, Lidya Suryani. "Ultimum Remedium Dalam Bidang Lingkungan Hidup." JURNAL HUKUM IUS QUIA IUSTUM 22, no. 1, 2015: 1-24. https://doi.org/10.20885/iustum.vol22.iss1.art1.

Yuherawan, DeniSB. "Kritik Ideologis Terhadap Dasar Kefilsafatan Asas Legalitas Dalam Hukum Pidana." Jurnal Dinamika Hukum 12, no. 2, May 15, 2012: 221-35. https://doi.org/10.20884/1.jdh.2012.12.2.32. 
